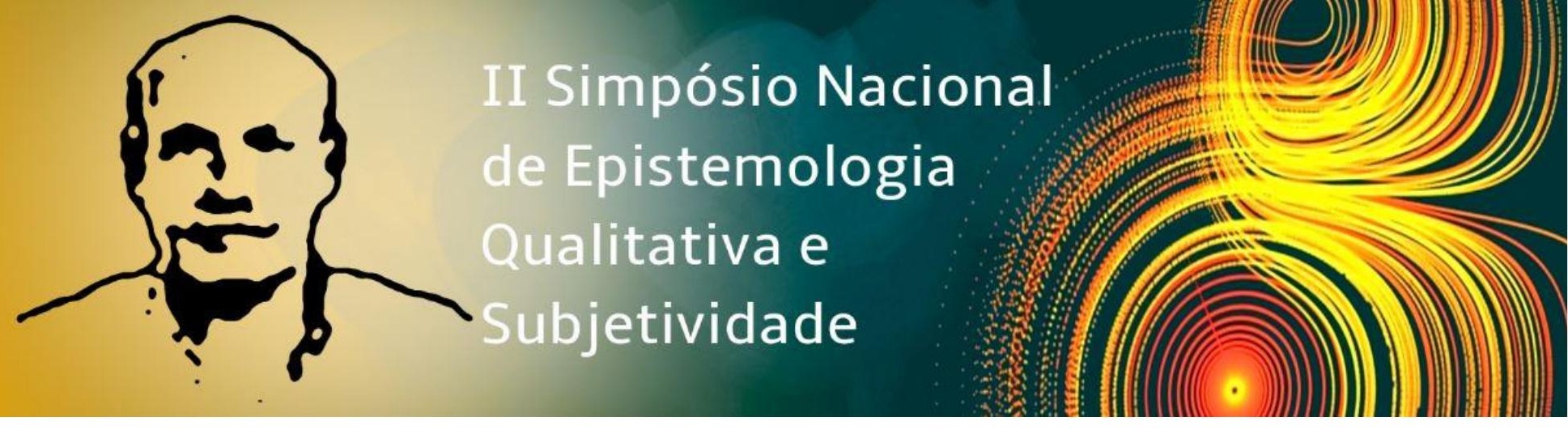

Eixo temático: Aprendizagem e dificuldade de aprendizagem na perspectiva da teoria da subjetividade

\title{
SUPERAÇÃO DAS DIFICULDADES DE APRENDIZAGEM EM BIOLOGIA
}

BEZERRA, Hanna Patrícia Silva, UFPA, IFAP, hannapatricia.06@gmail.com ALVES, José Moysés, UFPA, jmalves@ufpa.br

\section{Resumo}

As dificuldades de aprendizagem de estudantes do ensino médio em Biologia, normalmente são associadas a aspectos cognitivos e individuais, como a compreensão dos conteúdos científicos específicos, dificuldade de abstração e contextualização, falta de motivação e ausência de conhecimentos básicos, que deveriam ter sido constituídos em séries anteriores. Trabalhos sobre dificuldades de aprendizagem em Biologia como o de Dias; Núñez; Ramos (2010), descrevem estas dificuldades e discutem a importância da proposição de abordagens que transcendam a memorização. Normalmente, a superação das dificuldades de aprendizagem é vista, exclusivamente, acompanhando mudanças de metodologias de ensino, em que o professor substitui aulas expositivas por trabalhos práticos, experimentos ou atividades de campo, por exemplo. Considerando um ponto de vista diferente, defendemos o estudo da superação das dificuldades de aprendizagem de Biologia na perspectiva da Teoria da Subjetividade (MITJÁNS MARTÍNEZ; GONZÁLEZ REY, 2017), o que implica em considerar o processo de aprender como produção subjetiva que, além dos conteúdos a serem estudados, envolve os aspectos emocionais, simbólicos, culturais, históricos e sociais da vida de estudantes e professores. Nesse sentido, as dificuldades dos estudantes também são associadas a questões afetivas e sociais em que, abordagens metodológicas diferenciadas são relevantes, porém, mais importante é que as estratégias pedagógicas desenvolvam "recursos relacionais que orientam o professor na criação de canais dialógicos” (TACCA, 2014). Desse modo, Mitjáns Martínez; González Rey (2017) consideram que as ações pedagógicas devem favorecer a constituição do aprendiz como sujeito ativo e criativo de sua própria aprendizagem, gerando sentidos subjetivos 


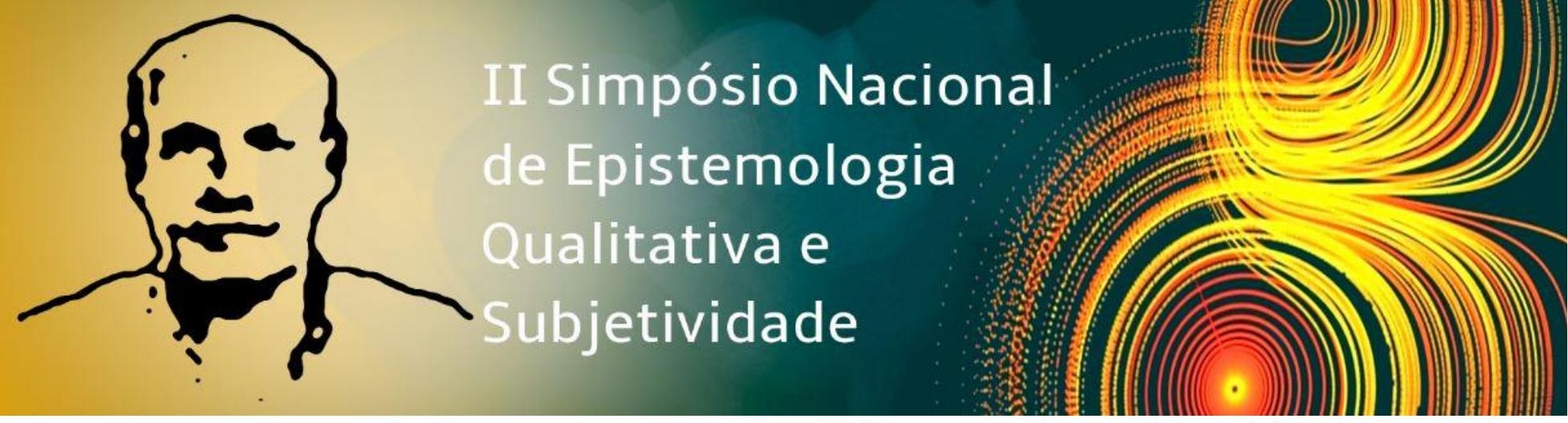

no processo de aprender. Logo, o presente resumo trata de uma pesquisa em desenvolvimento sobre os sentidos subjetivos produzidos por estudantes quando o ensino de Biologia é desenvolvido em contextos educativos que consideram a dimensão subjetiva no processo de aprendizagem. Apresentamos para o debate uma questão vinculada ao trabalho: Como investigar a superação das dificuldades de aprendizagem em biologia em uma perspectiva construtivo-interpretativa?

Palavras-chave: Superação de dificuldades de aprendizagem; Ensino de Biologia; Teoria da Subjetividade.

\section{Referências}

DIAS, M. A. S.; NÚÑEZ, I. B.; RAMOS, I. C. O. Dificuldades na aprendizagem dos conteúdos: uma leitura a partir dos resultados das provas de Biologia do vestibular da UFRN (2001 a 2008). In: Revista educação em questão, Natal, v. 37, n. 23, p. 219 - 243, jan/abr, 2010.

\section{GONZÁLEZ REY, F.L.; MITÍJANS MARTÍNEZ, A. Psicologia, Educação e}

Aprendizagem Escolar: avançando na contribuição da leitura cultural-histórica. São Paulo: Cortez, 2017.

TACCA, M. C. V. R. Estratégias pedagógicas: conceituação e desdobramentos com foco nas relações professor-aluno. In: TACCA, M. C. V. R. Aprendizagem e trabalho pedagógico. $3^{\mathrm{a}}$ ed. Campinas: Editora Alínea, 2014, p. 45 - 68. 